\title{
Quality, efficacy and safety of complementary medicines: fashions, facts and the future. Part I. Regulation and quality
}

\author{
Joanne Barnes \\ Centre for Pharmacognosy \& Phytotherapy, School of Pharmacy, University of London, London, UK
}

This is the first of two papers which review issues concerning complementary medicines. The first reviews the extent of use of complementary medicines, and issues related to the regulation and pharmaceutical quality of these products; the second considers evidence for the efficacy of several well-known complementary medicines, and discusses complementary-medicines pharmacovigilance. The term complementary medicines describes a range of pharmaceutical-type preparations, including herbal medicines, homoeopathic remedies, essential oils and dietary supplements, which mainly sit outside conventional medicine. The use of complementary medicines is a popular healthcare approach in the UK, and there are signs that the use of such products is continuing to increase. Patients and the public use complementary medicines for health maintenance, for the treatment or prevention of minor ailments, and also for serious, chronic illnesses. The pervasive use of complementary medicines raises several concerns. Many of these arise because most complementary medicines are not licensed as medicines, and therefore evidence of quality, efficacy and safety is not required before marketing. The regulatory framework for herbal medicines and dietary supplements is currently under review. A new system for registration of traditional herbal medicines will ensure that marketed products meet standards for quality and safety. At present, the pharmaceutical quality of many complementary medicines is a cause for concern.

Keywords: complementary medicines, dietary supplements, essential oils, herbal medicines, homoeopathic remedies, legislation, quality, regulation

\section{Introduction}

Complementary/alternative medicine (CAM) is an umbrella term for a collection of different approaches to diagnosis and treatment. Over 50 diverse complementary therapies have been listed, from homoeopathy (which involves the use of infinitely dilute preparations) to herbal medicine (which involves the use of chemically rich preparations of plant material), and from acupuncture (which involves the insertion of needles into specific points on the body) to spiritual healing (including 'distant' healing, which does not require the laying on of hands).

Several complementary therapies, such as herbalism, homoeopathy, aromatherapy and others, involve the administration of pharmaceutical-type remedies, e.g. herbal medicines, homoeopathic remedies and essential

Correspondence: Dr Joanne Barnes, Lecturer in Phytopharmacy, Centre for Pharmacognosy \& Phytotherapy, School of Pharmacy, University of London, 29-39 Brunswick Square, London WCIN IAX, UK. Tel.: + 44207753 5845; Fax:+ 44207753 5845; E-mail: joanne.barnes@ulsop.ac.uk

Received 10 May 2002, accepted 23 January 2003. oils (mainly used in aromatherapy) (see Table 1), collectively referred to as 'complementary medicines'. As well as being used by some CAM practitioners in their practice, these types of products are widely available for purchase for self-treatment from pharmacies, health-food stores, supermarkets, by mail order, via the internet and from other retail outlets.

This review discusses, mainly from a UK perspective, various types of complementary medicines, particularly trends in their use, regulation, and issues surrounding quality. A second review considers the evidence for the efficacy of complementary medicines and discusses issues related to their safety. Both reviews have a particular focus on European herbal medicines as these are among the most widely used 'complementary medicines' in the UK and, from a biomedical perspective, herbal medicines (rather than, for example, homoeopathic remedies) are likely to have the greatest potential in terms of both risks and benefits.

Herbal medicinal products are included in this overview of complementary medicines because, in the UK, patients, the public, the media and many other groups 
Table 1 Examples and descriptions of types of complementary medicines.

\begin{tabular}{|c|c|}
\hline $\begin{array}{l}\text { Anthroposophic } \\
\text { medicines }\end{array}$ & $\begin{array}{l}\text { Used as part of the anthroposophical approach to the treatment of illness. They are derived mainly from plant and mineral } \\
\text { sources; many are combinations of herbal ingredients. Particular attention is paid to the source and methods of farming } \\
\text { used in growing plant raw materials for preparing anthroposophic medicines (e.g. organic only). }\end{array}$ \\
\hline Ayurvedic medicines & $\begin{array}{l}\text { Used in Ayurveda, the traditional system of medicine of India. They are herbal/mineral preparations; heavy metals (e.g. lead, } \\
\text { arsenic) are sometimes used in the manufacturing process. }\end{array}$ \\
\hline $\begin{array}{l}\text { Dietary/food } \\
\text { supplements }\end{array}$ & $\begin{array}{l}\text { Preparations of substances commonly found in the diet, such as fish oils, or occurring naturally in the body, e.g. coenzyme } \\
\mathrm{Q}_{10} \text {. In the UK, many herbal products, e.g. garlic tablets, are sold as dietary/food supplements. }\end{array}$ \\
\hline Essential oils & $\begin{array}{l}\text { Aromatic substances extracted from plant material and which typically contain over } 100 \text { chemical constituents. Used mainly } \\
\text { in aromatherapy, most commonly applied in a carrier oil during massage. }\end{array}$ \\
\hline $\begin{array}{l}\text { Flower remedies/ } \\
\text { essences }\end{array}$ & $\begin{array}{l}\text { Flower remedies/essences are used to treat emotional and psychological symptoms, e.g. jealousy, indecision. The Bach } \\
\text { collection comprises } 39 \text { remedies, } 37 \text { of which originate from flowers/trees, one from natural spring water, and 'Rescue } \\
\text { Remedy', a combination of five of the other } 38 \text { remedies. Flower remedies are extremely dilute preparations, but are not } \\
\text { homoeopathic remedies. }\end{array}$ \\
\hline Herbal medicines & $\begin{array}{l}\text { Preparations made from plants or plant parts. In some instances (e.g. use by herbalists), crude drug (e.g. dried leaf) is used. } \\
\text { Manufactured products use extracts of plants or plant parts, formulated as, e.g. tablets, capsules, creams, tinctures. They } \\
\text { may contain a single or multiple herbal ingredients. }\end{array}$ \\
\hline $\begin{array}{l}\text { Homoeopathic } \\
\text { medicines }\end{array}$ & $\begin{array}{l}\text { Highly dilute preparations which may be of plant, animal, mineral, insect, biological, drug/chemical or other origin. } \\
\text { Formulations include pillules, tablets, creams/ointments, liquids, injections. }\end{array}$ \\
\hline $\begin{array}{l}\text { Traditional Chinese } \\
\text { herbal medicines }\end{array}$ & $\begin{array}{l}\text { Substances used as part of traditional Chinese medicine. Preparations may include animal parts and/or minerals, as well as } \\
\text { herbal material. }\end{array}$ \\
\hline $\begin{array}{l}\text { Vitamins and } \\
\text { minerals }\end{array}$ & $\begin{array}{l}\text { Single or multi-ingredient preparations of vitamins and/or minerals, sometimes in combination with other ingredients, e.g. } \\
\text { herbal drugs. It is a matter of debate whether vitamins and minerals should be considered to be complementary } \\
\text { medicines. }\end{array}$ \\
\hline
\end{tabular}

consider the use of herbal medicines, whatever the approach, including use of over-the-counter (OTC) herbal medicines, to be part of CAM. However, there is a view that herbal medicinal products with documented pharmacological activity and clinical efficacy lie alongside conventional medicines. Indeed, some herbal medicines, such as standardized senna preparations, are conventional medicines. In some countries, notably Germany, the use of plant drugs is an established science [1]. There, herbal medicinal products (also known as phytomedicines or phytotherapeutic agents) are prescribed in an evidencebased manner in an approach known as rational phytotherapy. This science- or evidence-based approach to the use of herbal medicines contrasts with traditional medical herbalism, and other traditional systems of healthcare (such as Ayurvedic, African and Chinese medicine) used in the UK, which can involve the use of herbs and which, generally, have not been subject to rigorous scientific investigation.

\section{Definitions and descriptions}

There is no specific definition for complementary medicines. This is not surprising given their diversity; herbal medicines are chemically rich preparations of plant material, whereas homoeopathic remedies are infinitely dilute preparations of material which may be plant, animal, mineral, chemical or biological in origin. Descriptions of different types of complementary medicines are given in Table 1. There are definitions for CAM [2, 3], including one adopted by the Cochrane Collaboration [3] (see Table 2), although these do not address specifically the pharmaceutical nature of complementary medicines.

Some organizations with an interest in a particular type of preparation have developed definitions. For example, the European Scientific Co-operative on Phytotherapy's (ESCOP) definition of phytomedicines (herbal medicines) is 'Phytomedicines, or herbal medicinal products, are medicinal products containing as active ingredients only plants, parts of plants or plant materials, or combinations thereof, whether in the crude or processed state' [4].

\section{Fashions? Prevalence of use of complementary medicines}

The use of complementary medicines is a popular healthcare approach in the UK, and there is evidence that the use of such products is increasing. A postal questionnaire survey carried out in England in 1998 and involving 5010 adults (response rate $=59 \%$ ) found that $22.1 \%$ of respondents (95\% confidence interval 20.5, 23.7; $n=585$ ) had purchased OTC homoeopathic or herbal medicines in the previous year [5]. Some other key findings are summarized in Table 3. Market research estimates that retail sales of complementary medicines (herbal medicines, homoeopathic remedies and essential oils) were worth f,115 million in 2000, representing growth of $23 \%$ since 1998 [6]. Herbal medicines represent $57 \%$ of sales of complementary medicines; this 
Table 2 Definition of complementary and alternative medicine (from Zollman and Vickers [3]).

'Complementary and alternative medicine (CAM) is a broad domain of healing resources that encompasses all health systems, modalities and practices and their accompanying theories and beliefs, other than those intrinsic to the politically dominant health system of a particular society or culture in a given historical period. CAM includes all such practices and ideas self-defined by their users as preventing or treating illness or promoting health and well-being. Boundaries within CAM and between the CAM domain and that of the dominant system are not always sharp or fixed.' [3]

Table 3 Selected findings of population-based survey of CAM use among adults $(n=2669)$ in England (from Thomas et al. [5]).

\begin{tabular}{|c|c|c|c|c|}
\hline \multirow[b]{2}{*}{ Therapy } & \multicolumn{2}{|c|}{$\begin{array}{l}\text { Use in } 12 \text { months } \\
\text { preceding the survey }\end{array}$} & \multicolumn{2}{|c|}{ Lifetime use } \\
\hline & $\%$ & $95 \% C I$ & $\%$ & $95 \% C I$ \\
\hline Homoeopathy & 1.2 & $0.8-1.6$ & 5.7 & $4.9-6.8$ \\
\hline Medical herbalism & 0.9 & $0.6-1.3$ & 4.4 & $3.6-5.1$ \\
\hline $\begin{array}{l}\text { OTC homoeopathic } \\
\text { medicine }\end{array}$ & 8.6 & $7.6-9.8$ & 14.6 & $13.3-16.0$ \\
\hline OTC herbal medicine & 19.8 & $18.3-21.3$ & 31.4 & $29.6-33.2$ \\
\hline
\end{tabular}

CI, Confidence intervals.

sector has shown growth of $50 \%$ for the period $1995-$ 2000.

Studies conducted in other developed countries also indicate high levels of use of and expenditure on complementary medicines. For example, in 1997 retail sales of herbal products in France and Germany, the two major European markets, were US $\$ 2.9$ billion [7] and, on the basis of findings from a survey in South Australia, it was estimated that in 1993 the Australian population spent \$AU621 on complementary medicines [8]. In the USA, annual retail sales of 'botanical' (herbal) medicines were estimated to be US\$1.6 billion in 1994 [9], and almost US\$4 billion in 1998 [10]. Data from nationwide surveys involving US adults indicate that the use of CAM is increasing. Use of at least one of 16 complementary therapies in the previous year had risen significantly from $33.8 \%$ of the sample in 1990 to $42.1 \%$ in 1997 $(P<0.001)$ [11]. Self-treatment with herbal medicines was one of the therapies showing the most increase over this period $(2.5 \%$ of sample in 1990 compared with $12.5 \%$ in $1997 ; P<0.001)$. Visits to herbal medicine practitioners also increased $(10.2 \%$ of sample in 1990 compared with $15.1 \%$ in 1997) [11].

In the UK, the use of complementary medicines is not limited to the private sector; in some cases, access is funded by the National Health Service (NHS). Homoeopathy is the best example of this; there are five NHS homoeopathic hospitals in the UK, and general practitioners (GPs) can prescribe homoeopathic preparations on NHS prescriptions. In 1998, over 150000 homoeopathic items were dispensed against NHS prescriptions; the net ingredient cost for these was $£ 927600$ (Prescription Pricing Authority, Personal communication. June 22 1999). (Net ingredient cost refers to the cost of the drug before discounts and does not include any dispensing costs or fees, or any adjustment for income obtained where a prescription charge is paid at the time the prescription is dispensed or where the patient has purchased a prepayment certificate.)

\section{Reasons for use}

\section{Symptoms and conditions}

Complementary medicines are used by the public both for general health maintenance and for the treatment of minor, self-limiting conditions. As most of these products are not licensed as medicines, manufacturers are not permitted to make medical claims for their products. However, as Vickers has shown, the lay literature and even several 'professional' texts in certain areas of complementary medicine, such as use of essential oils, encourage self-treatment of some serious conditions, in addition to making unsubstantiated medical claims [12].

A study of 1337 community pharmacists (response rate 69\%) found that herbal products used to help relieve stress and sleep problems were the herbal medicines most frequently requested by pharmacy clientele and 'recommended' by pharmacists to their customers as a result of consultations regarding symptoms [13]. Previously, a study carried out in 1996 and comprising interviews with 515 users of herbal medicines [14] found that herbal products to help relieve stress and sleep problems, garlic preparations and evening primrose and starflower oil products were those most frequently used by participants [13]. Garlic preparations were used for a variety of reasons, mostly related to maintaining a 'healthy heart', circulation, blood pressure, and 'for cholesterol', but also for 'general health', colds, 'improving the immune system', stomach aches and tiredness. Garlic products have not been shown to be of benefit in all of these areas.

Further evidence that use of complementary medicines is not limited to use in conditions supported by evidence, or to symptoms or conditions suitable for OTC treatment, comes from numerous studies of the use of CAM by patients with serious chronic illnesses, including cancer [15-18], HIV/AIDS [19], multiple sclerosis [20, 21], 
rheumatological conditions [22], asthma [23, 24], depression [11, 25], gastroenterological problems [26] and other disorders [27]. In addition, complementary medicines are used by specific patient groups, such as the elderly [2830] and pregnant or breast-feeding women [31], and are administered by parents/guardians to children [32-34].

\section{Beliefs, perceptions and attitudes}

There are numerous reasons why people choose to use complementary medicines and therapies. They include dissatisfaction with conventional medicine in terms of effectiveness and/or safety, satisfaction with CAM, and the perception that it is inherently safe [35, 36], to more complex reasons that are associated with cultural and personal beliefs and philosophical views on life and health [37], and experiences with conventional healthcare professionals and complementary-medicine practitioners [38]. Furthermore, decisions about which CAM options to use are based on a combination of beliefs about science, health and healthcare [39, 40].

An individual's choice to use CAM approaches is tied in with 'healthcare pluralism'. This term describes the fact that when people become ill they have available to them numerous treatment options and ways of seeking advice and help, including taking advice from family/friends, consulting a CAM practitioner and consulting a pharmacist, GP or other healthcare professional [41]. Related issues include whether individuals are willing to disclose CAM use to conventional healthcare professionals, and whether there is better compliance (or adherence) with complementary-medicines regimens than with conventional drug regimens.

\section{Regulation of complementary medicines}

The pervasive use of complementary medicines raises several concerns. Many of these stem from the fact that most complementary health products are not licensed as medicines and therefore evidence of their quality, efficacy and safety has not been assessed by the competent authority which, in the UK, is the Medicines Control Agency (MCA).

\section{Herbal medicines}

Herbal products are available on the UK market as licensed herbal medicines, herbal medicines exempt from licensing, or unlicensed herbal products sold as food supplements. In several cases, the same herb is available in all three legal categories. Potentially hazardous plants are controlled as prescription-only medicines (POM) and certain others are subject to dose (but not duration of treatment) and route of administration restrictions, or can be supplied only via a pharmacy and by, or under the supervision of, a pharmacist [42, 43].

Most licensed herbal products were initially granted a product licence of right (PLR) because they were already on the market when the licensing system was introduced in the 1970s. When PLRs were reviewed, manufacturers of herbal products intended for use in minor self-limiting conditions were permitted to rely on bibliographic evidence to support efficacy and safety, rather than being required to carry out new controlled clinical trials [44]. So, many licensed herbal medicinal products have not necessarily undergone stringent testing.

Herbal products exempt from licensing (specified under Sections 12(1) and 12(2) of the Medicines Act 1968) are those compounded and supplied by herbalists on their own recommendation, and those consisting solely of dried, crushed or comminuted (fragmented) plants (i.e. they must not contain any nonherbal 'active' ingredients) sold under their botanical name and with no written recommendations for use, and those made by the holder of a specials manufacturing licence on behalf of a herbalist [44]. This category was initially intended to give herbalists the flexibility to prepare remedies for their patients, although, at present, there is no statutory regulation of herbalists in the UK (this is under review). Herbal medicines that are 'industrially produced' are required to hold a marketing authorization, but as this term is not defined in law, small-scale manufacturers have been permitted to sell products legally under the exemption [44].

Most herbal products are sold as food supplements without making medical claims and are regulated under food, not pharmaceutical, legislation [44]. In the UK, the MCA has the statutory power to decide whether a specific product satisfies the definition of a relevant 'medicinal product' and therefore is subject to the provisions of regulations relating to Medicines for Human Use $[45,46]$. If a product is determined to be a relevant medicinal product, and if it does not meet criteria for exemption, then the manufacturer is required to submit an application for a full product licence and/or remove the product from the market. The procedure allows for the company to request a review of the decision. In this case, the views of an independent panel are taken into consideration [47].

'Ethnic' medicines available in the UK include traditional Chinese herbal medicines (TCHM) and Ayurvedic medicines (see Box 1). Such products are subject to the same legislation as are 'Western' complementary medicines. In the UK, there are further restrictions on certain toxic herbal ingredients, namely Aristolochia species, found in some TCHM products, and on other herbal ingredients that may be confused with toxic herbal ingredients [48]. In addition to containing nonherbal ingredi- 
ents such as animal parts and/or minerals, some manufactured ('patent') TCHM products have been found to contain conventional drugs as listed ingredients, some of which (e.g. glibenclamide) may have POM status in the UK. Non-herbal active ingredients of any type cannot legally be included in unlicensed herbal remedies, and inclusion of drugs with POM status represents an additional infringement of UK medicines legislation. For some ingredients, such as certain animal parts, restrictions under the Convention on International Trade in Endangered Species of Wild Fauna and Flora (CITES) also apply [43].

There is a widely held opinion that the current system of licensing for herbal medicines does not give consumers adequate protection against poor-quality and unsafe "unlicensed" herbal products, nor does it allow manufacturers of unlicensed products to provide appropriate information to inform consumers' choice of products. Against this background, there is now a draft European Union (EU) directive which aims to establish a harmonized legislative framework for authorizing the marketing of traditional herbal medicinal products [49]. The directive will require EU member states to set up a specified simplified registration procedure for traditional herbal medicinal products which could not fulfil medicines licensing criteria. Some of the main features of this are that manufacturers will be required to provide:

- evidence that the herb has been used traditionally in the EU for at least 30 years (15 years' non-EU use will be taken into account)

- bibliographic data on safety with an expert report

- a quality dossier demonstrating manufacture according to principles of good manufacturing practice (GMP).

The new directive is not a route to licensing for prescription-only medicines or for traditional herbal medicines that 'can' be licensed by the conventional route. As it stands, the proposed directive would accommodate ethnic medicines that have been used in the UK (or any other member state) for at least 15 years.

In January 2002, the European Commission adopted formal proposals for the directive [50], although amendments to it may yet be made. It is intended that the directive will be in force by the end of 2004 .

\section{Homoeopathic remedies}

In the UK, homoeopathic remedies are subject to medicines legislation. A simplified registration scheme exists in the UK (and the rest of the EU) for homoeopathic medicinal products which are intended for oral or external use, sufficiently dilute (usually a minimum dilution of 1 in 10000 ) and where no medical claims are made. For such products, manufacturers are required to dem- onstrate quality and safety, but not efficacy [51]. Manufacturers of homoeopathic medicinal products which are administered parenterally, are below the minimum dilution or make efficacy claims are required to substantiate this in the same manner as is required for conventional drugs.

\section{Other complementary medicines}

Products marketed as food or dietary supplements (see Regulation of complementary medicines, Herbal medicines) include nonherbal substances, such as glucosamine, vitamins, minerals and fish oils. Like unlicensed herbal medicines, these products are sold under food legislation and are marketed without medical claims. Such products may be deemed by the MCA to be a relevant medicinal product (see Regulation of complementary medicines, Herbal medicines). Some 'supplements' are subject to stringent restrictions on their use. Melatonin is a prescription-only medicine, available on a 'named patient' basis only as there are no licensed melatonin products in the UK [52]. However, in the USA, melatonin is sold as a food supplement. A new draft EU directive is aimed at harmonizing the marketing of food supplements in member states [53].

Essential oils used by aromatherapists in their practice for medicinal purposes are considered to be medicinal products, but are exempt from licensing provided they meet the criteria under Section 12(1) of the Medicines Act 1968 (see Regulation of complementary medicines, Herbal medicines). Aromatherapy products sold through retail outlets are not subject to licensing regulations unless they are marketed as medicinal products [54]. Some essential oils are available as licensed medicinal products, e.g. peppermint oil capsules [55], although such products are conventional medicines, not aromatherapy products.

\section{Quality}

The quality of marketed products is generally not an issue with conventional medicines but, at present, for some complementary medicines, this is a real concern. Manufacturers of licensed medicines, including licensed complementary medicines, are required to demonstrate to the MCA that their products meet standards for pharmaceutical quality (as well as safety and efficacy), i.e. that they are manufactured in accordance with the principles of GMP. However, manufacturers of unlicensed products are not required to do this and therefore there is no guarantee that such products meet standards for pharmaceutical quality, including, for example, that the product contains what is stated on the label (although this would be an issue for Trading Standards). Some established manufacturers of unlicensed products do have suitable in- 
house quality control and quality assurance procedures and manufacture their products according to the principles of GMP. However, others do not. This section discusses quality issues, particularly in relation to herbal medicinal products.

\section{Variable composition}

Ensuring that complementary medicines, particularly plant-based products, are of suitable quality is important for several reasons. Herbs are natural products and, thus, do not have a consistent, standardized composition; the difference in vintages of wines has been used as an analogy [1]. Plants contain numerous chemical constituents; at least 50 or so, but most contain many more (up to several hundred in some cases); and different parts of the plant (e.g. roots, leaves) contain a different profile of constituents. Furthermore, the content and concentration of constituents can be influenced by several factors. These include climate, growing conditions, time of harvesting, and postharvesting factors, such as storage conditions (e.g. light, temperature, humidity), and processing (e.g. extraction and drying) [56].

For these reasons, batch-to-batch and manufacturerto-manufacturer variation in preparations of the same herb will occur; it is important to emphasize that products from different manufacturers are not the same. For example, analysis of eight St John's wort products available in the USA found that their hyperforin content varied from $0.01 \%$ to $1.89 \%$ [57], and only two products contained sufficient hyperforin likely to be required for antidepressant effects. Similarly, the products' hypericin content varied from $0.03 \%$ to $0.29 \%$ and, for several products, the actual hypericin content did not correlate with that stated on the product label (range $57-130 \%$ of label claim).

\section{Contamination}

The quality of plant raw materials can also be influenced by human error or unscrupulous operators. Accidental botanical substitution (misidentification of plant species) or intentional botanical substitution (deliberate exchange with other, possibly more toxic, plant species) can occur. An example of this, and one which resulted in significant morbidity, relates to reports which first surfaced in the 1990s, initially from Belgium and, later, from the UK, of renal failure and renal cancer following the use of slimming products contaminated with Aristolochia species [44]. This was due to the substitution of nontoxic herbs, including Stephania tetrandra and Clematis armandii, with Aristolochia species. Accidental or intentional contamination of herbal material with conventional drugs (e.g. corticosteroids) or poisonous substances (e.g. heavy met- als, pesticide residues) and microorganisms can also occur $[44,56]$. For example, there have been reports of Chinese 'herbal' creams containing corticosteroids [58], and of Ayurvedic remedies from the Indian subcontinent containing heavy metals [59]. Similar deficiencies in the quality of some 'homoeopathic' remedies have also been reported [60,61]. In some cases, the products concerned originated from outside the UK [61]. Adulteration of essential oils is stated to be widespread [62].

\section{Standardization}

The variability in the content and concentrations of constituents of plant material, together with the range of extraction techniques and processing steps used by different manufacturers, results in marked variability in the content and quality of commercially available herbal products [1]. Several manufacturers now produce standardized herbal extracts as an approach to achieving more consistent pharmaceutical quality, at least within manufacturer (i.e. batch-to-batch consistency). Such products are manufactured to contain a specific quantity of the active constituent(s) and, in some cases, unwanted or toxic constituents are removed. For example, standardized extracts of Ginkgo biloba contain 22-27\% ginkgo flavonoid glycosides, $5-7 \%$ terpene lactones, and less than 5 parts per million of ginkgolic acids, which are known to be allergenic.

Standardization is an important step where the active constituents are known. However, for many herbs the active constituents are not known. In these cases, products may be standardized on content of certain 'marker' compounds (chemicals characteristic of the herb, or present in large quantities). However, this approach makes assumptions about the relationship between the quantity of marker compounds and that of the unknown active constituents [1]. In other cases, new evidence on active constituents has emerged. For example, hypericin was originally thought to be the active antidepressant constituent of extracts of St John's wort, and preparations were standardized on their content of this compound [63]. However, new experimental [64, 65] and clinical evidence [66] indicates that hyperforin is a major antidepressant constituent. Nevertheless, St John's wort extracts continue to be standardized on hypericin content, as hyperforin is thought to be relatively unstable $[67,68]$.

Examples of problems with ethnic medicines were used to illustrate several of the quality issues outlined above. In the UK, the quality and safety standards of ethnic medicines are a particular concern. For example, it is recognized that some practitioners, suppliers and manufacturers in the TCHM sector lack quality controls, so that some TCHM products available on the UK market are of poor quality, some are illegal, and there 
are isolated cases of products which are potentially dangerous [69].

In 2000, the MCA set up an Ethnic Medicines Forum which aims to help and encourage the ethnic medicines sector to achieve improvements to safety and quality standards in relation to unlicensed ethnic medicines, and to raise awareness of medicines legislation among some operators within the sector [43]. The Forum includes representatives of the TCHM and Ayurvedic sectors in the UK (e.g. suppliers, manufacturers and practitioners), MCA and other herbal medicine organizations.

In conclusion, given the pervasive use of complementary medicines, initiatives to address the poor quality of some complementary medicines, particularly some herbal products and ethnic medicines, are in the public's best interests and therefore are essential.

The author thanks Dr Linda Anderson and Professor J. David Phillipson for helpful discussions during the preparation of this paper, and the referees for their comments.

J.B. has received research funding and hospitality from Lichtwer Pharma UK Ltd, manufacturer of LI-1370 and LI-160, and held a Lichtwer Pharma Research Fellowship (August 1999 to July 2002). J.B. held a research fellowship (February 1996 to July 1999) funded by Boots, retailer of herbal medicines, and has received hospitality from Bioforce (UK) Ltd, manufacturer of herbal medicines.

\section{References}

1 Schulz V, Hänsel R, Tyler VE. Rational Phytotherapy. A Physicians' Guide to Herbal Medicine, Fourth edition. Berlin: Springer, 2000.

2 Ernst E, Resch KL, Mills S, Willoughby M. Complementary medicine-a definition. Br J General Prac 1995; 48: 506.

3 Zollman C, Vickers A. What is complementary medicine? $\mathrm{Br}$ Med J 1999; 319: 693-696.

4 European Scientific Co-operative on Phytotherapy URL: http://www.escop.com [accessed 28 February 2002].

5 Thomas KJ, Nicholl JP, Coleman P. Use and expenditure on complementary medicine in England: a population based survey. Complement Ther Med 2001; 9: 2-11.

6 Mintel International Limited. Complementary Medicines. Market Intelligence. London: Mintel International Ltd, 2001.

7 Institute of Medical Statistics (IMS) Self-Medication International. Herbals in Europe. London: IMS SelfMedication International, 1998.

8 MacLennan AH, Wilson DH, Taylor AW. Prevalence and cost of alternative medicine in Australia. Lancet 1996; 347 : 569-573.

9 Brevoort P. The US botanical market-an overview. Herbalgram 1996; 36: 49-57.

10 Brevoort P. The booming US botanical market. A new overview. Herbalgram 1998; 44: 33-46.

11 Eisenberg DM, Davis RB, Ettner SL et al. Trends in alternative medicine use in the United States, 1990-97. Results of a national follow-up survey. JAMA 1998; 280: 1569-1575.
12 Vickers A. Massage and Aromatherapy. A Guide for Health Professionals. London: Chapman \& Hall, 1996.

13 Barnes J. An examination of the role of the pharmacist in the safe, effective and appropriate use of complementary medicines (PhD Thesis). University of London, 2001.

14 Barnes J, Mills SY, Abbot NC, Willoughby M, Ernst E. Different standards for reporting ADRs to herbal remedies and conventional OTC medicines: face-to-face interviews with 515 users of herbal remedies. Br J Clin Pharmacol 1998; 45: 496-500.

15 Ernst E, Cassileth BR. The prevalence of complementary/ alternative medicine in cancer. A systematic review. Cancer 1998; 83: 777-782.

16 Verhoef MJ, Hagen N, Pelletier G, Forsyth P. Alternative therapy use in neurologic diseases. Use in brain tumour patients. Neurology 1999; 52: 617-622.

17 Burstein HJ, Gelber S, Guadagnoli E, Weeks JC. Use of alternative medicine by women with early-stage breast cancer. New Engl J Med 1999; 340: 1733-1739.

18 Lippert MC, McClain R, Boyd JC, Theodorescu D. Alternative medicine use in patients with localized prostate cancer treated with curative intent. Cancer 1999; 86: 26422648.

19 Fairfield KM, Eisenberg DM, Davis RB, Libman H, Phillips RS. Patterns of use, and perceived efficacy of complementary and alternative therapies in HIV-infected patients. Arch Int Med 1998; 158: 2257-2264.

20 Huntley A, Ernst E. Complementary and alternative therapies for treating multiple sclerosis: a systematic review. Comp Ther Med 2000; 8: 97-105.

21 Tremlett HL, Wiles CM, Luscombe DK. Non-prescription medicine use in a multiple sclerosis clinic population. $\mathrm{Br} J$ Clin Pharmacol 2000; 50: 55-60.

22 Ernst E. Usage of complementary therapies in rheumatology: a systematic review. Clin Rheumatol 1998; 17: 301-305.

23 Lamb C, Cantrill JA. Asthma patients' usage of over-thecounter medicines and complementary remedies. Pharm J 1995; 254: 802-804.

24 Ernst E. Complementary therapies for asthma: what patients use. J Asthma 1998; 35: 667-671.

25 Ernst E, Rand JI, Stevinson C. Complementary therapies for depression. An overview. Arch General Psychiatr 1998; 55: 1026-1032.

26 Rawsthorne P, Shanahan F, Cronin NC et al. An international survey of the use and attitudes regarding alternative medicine by patients with inflammatory bowel disease. Am J Gastroenterol 1999; 94: 1298-1303.

27 Ernst E. The usage of complementary therapies by dermatological patients: a systematic review. Br J Dermatol 2000; 142: 857-861.

28 Sleath B, Rubin RH, Campbell W, Gwyther L, Clark T. Ethnicity and physician-older patient communication about alternative therapies. J Altern Complement Med 2001; 7: 329335.

29 Flaherty JH, Takahashi R, Teoh J et al. Use of alternative therapies in older outpatients in the United States and Japan: prevalence, reporting patterns, and perceived effectiveness. J Gerontol A Biol Sci Med Sci 2001; 56: M650-M655.

30 Brazier N, Bédard M, Brazil K et al. The use of natural health 
products (NHP) by Ontario seniors. Clin Pharmacol Ther 2001; (Feb): 14 [Abstr.]

31 Hemminki E, Mantyranta T, Malin M, Koponen P. A survey on the use of alternative drugs during pregnancy. Scand J Soc Med 1991; 19: 199-204.

32 Ernst E. Prevalence of complementary/alternative medicine for children: a systematic review. Eur J Pediatr 1999; 158: 711.

33 Simpson N, Pearce A, Finlay F, Lenton S. The use of complementary medicine in paediatric outpatient clinics. Ambulatory Child Health 1998; 3: 351-356.

34 Moenkhoff M, Baenziger O, Fischer J, Fanconi S. Parental attitude towards alternative medicine in the paediatric intensive care unit. Eur J Pediatr 1999; 158: 12-17.

35 Abbot NC, Ernst E. Patients' opinions about complementary medicine. Forschende Komplementärmedizin 1997; 4: 164-168.

36 Ernst E, White A. The BBC survey of complementary medicine use in the UK. Complement Ther Med 2000; 8: 3236.

37 Astin JA. Why patients use alternative medicine. Results of a national study. JAMA 1998; 279: 1548-1553.

38 Furnham A. Why do people choose and use complementary therapies?. In Complementary Medicine. An Objective Appraisal, ed. Ernst E, Oxford: Butterworth-Heinemann, 1996.

39 Vincent C, Furnham A. Knowledge, attitudes and beliefs of patients of complementary practitioners. In Complementary Medicine. A Research Perspective, eds Vincent C, Furnham A, Chichester: Wiley, 1997.

40 Furnham A, Vincent C, Wood R. The health beliefs and behaviors of three groups of complementary medicine and a general practice group of patients. J Altern Complement Med 1995; 1: 347-359.

41 Helman C. Culture, Health and Illness, Fourth edition, Oxford: Butterworth-Heinemann, 2000: 50-78.

42 Appelbe GE, Wingfield J. Dale and Appelbe's Pharmacy Law and Ethics, Sixth Edition, London: Pharmaceutical Press, 1997.

43 Medicines Control Agency. Traditional ethnic medicines. Public Health and Compliance with Medicines Law, London: Medicines Control Agency, November 2001, URL: http:// www.mca.gov.uk

44 Barnes J, Anderson LA, Phillipson JD. Herbal Medicines. A Guide for Healthcare Professionals, Second Edition, London: Pharmaceutical Press, 2002.

45 The Medicines for Human Use (Marketing Authorisations Etc.) Regulations 1994 (SI 1994/3144). London: The Stationery Office.

46 The Medicines for Human Use (Marketing Authorisations Etc.) Amendment Regulations 2000 (SI 2000/292). London: The Stationery Office.

47 Medicines Control Agency. Regulatory framework: Independent Review Panel on the Classification of Borderline Products. URL: http://www.mca.gov.uk/ [accessed 22 March 2002].

48 The Medicines (Aristolochia and Mu Tong etc) (Prohibition) Order, 2001 (SI 2001/1841). London: The Stationery Office.

49 Commission of the European Communities. Proposal for Amending the Directive 2001/83/EC as Regards Traditional Herbal Medicinal Products. 2002/0008. Brussels: European Commission, 17 January 2002.
50 Medicines Control Agency. Briefing on draft directive on traditional herbal medicinal products. March 4 2002. URL: http://www.mca.gov.uk/ [accessed 22 March 2002].

51 Kayne S. Homoeopathic Pharmacy. Edinburgh: Churchill Livingstone, 1997: 59-63.

52 Rapport L, Lockwood B. Nutraceuticals. London: Pharmaceutical Press, 2002.

53 Mason P. Dietary Supplements, Second Edition. London: Pharmaceutical Press, 2001.

54 Buckle J. Clinical Aromatherapy in Nursing. London: Arnold, 1997: 262.

55 British Medical Association and Royal Pharmaceutical Society of Great Britain. British National Formulary 42, September, 2001. London: British Medical Association and Royal Pharmaceutical Society of Great Britain, 2001.

56 Bisset NG, ed. Herbal Drugs and Phytopharmaceuticals, ed. (German edition), Wichtl M. Stuttgart: Medpharm, 1994.

57 De los Reyes GC, Koda RT. Determining hyperforin and hypericin content in eight brands of St John's wort. Am J Health Syst Pharm 2002; 59: 545-547.

58 Keane FM, Munn SE, du Vivier AW, Taylor NF, Higgins EM. Analysis of Chinese herbal creams prescribed for dermatological conditions. Br Med J 1999; 318: 563-564.

59 Ernst E. Toxic heavy metals and undeclared drugs in Asian herbal medicines. Trends Pharmacol Sci 2002; 23: 136139.

60 Kerr HD, Saryan LA. Arsenic content of homeopathic medicines. Clin Toxicol 1986; 24: 451-459.

61 Morice A. Adulterated 'homoeopathic' cure for asthma. Lancet 1986; 1: 862-863.

62 Tisserand R, Balacs T. Essential Oil Safety. A Guide for Health Care Professionals. Edinburgh: Churchill Livingstone, 1995: 9.

63 Barnes J, Anderson LA, Phillipson JD. St John's wort (Hypericum perforatum L.): a review of its chemistry, pharmacology and clinical properties. J Pharm Pharmacol 2001; 53: 583-600.

64 Chatterjee SS, Bhattacharya SK, Wonnemann M, Singer A, Muller WE. Hyperforin as a possible antidepressant component of hypericum extracts. Life Sci 1998; 63: 499510.

65 Chatterjee SS, Noldner M, Koch E, Erdelmeier C. Antidepressant activity of Hypericum perforatum and hyperforin: the neglected possibility. Pharmacopsychiatry 1998; 31 (Suppl): $7-15$.

66 Laakmann G, Schüle C, Baghai T, Kieser M. St John's wort in mild to moderate depression: the relevance of hyperforin for the clinical efficacy. Pharmacopsychiatry 1998; 31 (Suppl): 54-59.

67 Verotta L, Appendino G, Belloro E, Jakupovic J, Bombardelli E. Hyperforin analogues from St John's wort (Hypericum perforatum). J Nat Prod 2000; 63: 412-415.

68 Orth HCJ, Rentel C, Schmidt PC. Isolation, purity analysis and stability of hyperforin as a standard material from Hypericum perforatum L. J Pharm Pharmacol 1999; 51: 193200.

69 Medicines Control Agency. Press release. Concern over quality and safety standards of traditional Chinese medicines (2001/0448), 27 September 2001. URL: http:// www.mca.open.gov.uk [accessed 22 March 2002]. 